\title{
Beck's Personality Beliefs Questionnaire: Evidence of Validity and Reliability of the Russian Version
}

\author{
Elena I. Rasskazova ${ }^{\mathrm{a}, \mathrm{b}^{*}}$ \\ ${ }^{a}$ Lomonosov Moscow State University, Moscow, Russia \\ ${ }^{\mathrm{b}}$ Mental Health Research Center, Moscow, Russia \\ * Corresponding author. E-mail: e.i.rasskazova@gmail.com
}

Background. The cognitive model of personality disorders has differentiated 10 patterns of dysfunctional beliefs that lead to specific deficient and highly developed coping strategies. The Personality Belief Questionnaire (PBQ) is a self-report instrument based on this model, which differentiates patients with avoidant, dependent, obsessive-compulsive, narcissistic, paranoid, histrionic, passive-aggressive, antisocial, and borderline disorders from each other and from patients with other mental illnesses.

Objective. To validate the Russian version of the PBQ in clinical and control samples.

Design. The PBQ was translated and back-translated. 591 adults without mental illnesses and 200 in patients with different mental illnesses (predominantly affective disorders, personality disorders, schizotypal disorder, and schizophrenia) filled out the Russian version of the PBQ. 178 participants from the control sample and all 200 patients also filled out the Symptom Checklist-90 Revised. 78 participants from the control sample and 58 patients filled out the Millon Clinical Multiaxial Inventory- III. 54 participants from the control sample filled out the PBQ again after three weeks to check for test-retest reliability.

Results. The Russian version of the PBQ demonstrated good consistency (Cronbach's alphas .74- .88) in both samples and test-retest stability $(r=.54-.76)$ in the control sample. In line with previous findings, there were high correlations between the scales. Higher scores for avoidant, dependent, passive-aggressive, paranoid, and borderline beliefs and probably histrionic beliefs are typical for patients with different mental illnesses compared to the control sample and especially for patients with schizotypal disorder. The convergent and discriminant validity of the PBQ are supported by specific correlations with clinical personality patterns both in the controls and the clinical sample. Any dysfunctional beliefs are related to more general psychopathological complaints.

Conclusion. The data support the validity and reliability of the Russian version of the PBQ. Both in the control and clinical samples, dysfunctional beliefs have a mixed structure and are related to general psychopathology.

Keywords: reliability; mental illnesses; cognitive model of personality disorders; validation; Personality Beliefs Questionnaire 


\section{Introduction}

There is a long tradition of psychological interest in personality disorders, including diagnostically significant indicators differentiating borderline personality from other personality structures (Kernberg, 1984; Sokolova, 2015). A number of structured measures aimed to achieve correspondence between psychological constructs and clinical classifications (predominantly DSM). Among the most famous is the Minnesota Multiphasic Personality Inventory (MMPI, Butcher et al., 2001), which was based on an "empirical keying" strategy but then included psychometrical proof and theoretical interpretation for many scales (Tellegen et al., 2008), and the Millon Clinical Multiaxial Inventory (MCMI, Millon, 2009), which was developed in accordance with T. Millon's personality theory.

According to the cognitive approach (Beck, Davis, \& Freeman, 2015), there are dysfunctional core beliefs that make people feel the need to defend themselves. Intermediate beliefs defending the personality are specific to different personality disorders and lead to the development of some coping strategies and a deficiency of others. For instance, a person with the core belief "I'm vulnerable. Everybody can hurt me" could say to herself: "To defend myself I should never trust others" (typical of paranoid personality disorder). As a consequence, her abilities and strategies to be alert and defensive would be highly developed, while abilities to form close relationships and trust would be deficient. The same core belief could be transformed to another intermediate belief: "If I attack first, I could defend myself", leading to symptoms of antisocial personality disorder.

Based on this theory, in 1991 A.T. Beck and J.S. Beck developed the Personality Belief Questionnaire - a self-report instrument including 126 items describing beliefs typical of people with different personality disorders (according to DSM-IV): avoidant, dependent, obsessive-compulsive, narcissistic, paranoid, histrionic, passive-aggressive, antisocial, schizoid (Beck et al., 2001). The validation study comprised 756 outpatients, including 128 patients with Axis I but no Axis II disorders (controls) and patients with different Axis II disorders. The study supported good scale consistency (Cronbach's alphas .81. -.93$)$, test-retest reliability $(\mathrm{r}=.57-.93)$, and criteria validity (patients with avoidant, dependent, obsessive-compulsive, paranoid, and narcissistic disorders scored higher on the corresponding beliefs than other patients). The study, using the short version of the PBQ, also demonstrated the highest scores on corresponding scales for patients with avoidant, dependent, obsessive-compulsive, paranoid, and narcissistic disorders (Fournier et al., 2012).

However, we could not find any studies supporting factor validity of the first (full) version of the questionnaire, which is reasonable taking into account the high comorbidity of different personality disorders as well as the close relationships between different dysfunctional beliefs (Beck et al., 2015). A study of the short version of the PBQ using confirmatory and exploratory analysis showed (Fournier et al., 2012) that exploratory factor analysis reveals a 7-factor structure instead of a 9- or 10-factor structure, with mixed Avoidant and Dependent scales, Antisocial and Narcissistic scales, and interference of some items having higher loading on other factors. Confirmatory factor analysis in this study support the same 7 -factor structure with an "acceptable" fit. This mixed structure is in line with A. Beck's idea (Beck et al., 2015) that different conditional beliefs in personality disorders have 
the same source in basic beliefs. Moreover, some contrary beliefs (e.g., avoidant and dependent ones) could be highly positively correlated, indicating general problems (or sensitivity to such problems) in interpersonal relationships.

The Borderline Personality Disorder scale of the PBQ was developed later (Butler, Brown, Beck, \& Grisham, 2002) by indicating 14 items from the PBQ that differentiate 84 patients with borderline personality disorder and 204 patients with other personality disorders. The items described dependency, helplessness, distrust, fear of rejection or loss of emotional control, and attention-seeking behavior and were initially developed for the Dependent, Paranoid, Avoidant, and Histrionic scales.

The PBQ did not become as popular in clinical practice as MCMI or MMPI, but is a widespread practical tool that has been translated into many languages including Spanish, Norwegian, Polish, Brazilian Portuguese, Argentine Spanish, and Turkish (e.g., Aktas, Guriz, Alpaslan, Cavdar, \& Orsel, 2015; Moretti, Trógolo, Dominguez-Lara, Conn, \& Medrano, 2018; Hernández, Darío, Vasquez, \& Semenova, 2015; Zawadski, Popiel, Praglowska, \& Newman, 2017) and is used not only in clinical samples but also in healthy controls (Ryan, Kumar, \& Wagner, 2015; Thimm, Jordan, \& Bach, 2016), patients with functional and somatic illnesses (Taymur et al., 2015) and people with drug addictions (Albein-Urios, MartinezGonzález, \& Lozano, 2014). Some reviews consider the PBQ as a relevant instrument for DSM-V as well (e.g., Bhar, Beck, \& Butler, 2012). There is also a brief version of the PBQ that was developed by statistical choice of the "best" items for each scale (Butler, Beck, \& Cohen, 2007) and a modified version (Zawadski et al., 2017), changed for better between-group differentiation.

The aim of the present study was to validate the Russian version of the PBQ in clinical and control samples. This study started in 2009, with the permission of Dr. A. Beck. Since that time, another Russian version of the PBQ was independently developed by A.B. Kholmogorova and her colleagues (Kargin, Kholmogorova, \& Vojtseh, 2009). However, when looking for published psychometric characteristics for this variant, we could find them only for the 14-item Borderline Personality Disorder scale (PBQ-BPD), which was first translated and used for the study of male prostitution (Maximov \& Kholmogorova, 2011) and was validated in samples of 543 Internet users, 35 patients with schizoaffective disorders, and 50 males involved in male prostitution (Konina \& Kholmogorova, 2016). Unfortunately, we could not find any published detailed psychometric characteristics of this version of the $\mathrm{PBQ}$, but we compared the published characteristics for the Borderline scale. Below we compare the psychometric characteristics for these two Russian versions of the Borderline scale. Studies using the full version of the PBQ with Russian samples concentrate on specific clinical phenomena - suicidal behavior (Kargin et al., 2009), social anxiety in patients with affective disorders (Nikitina, Kholmogorova, \& Krasnova, 2012). The first paper bases its description of the test on English references only, while the second mentions that the validation is incomplete.

To our knowledge, this is the first study to demonstrate the consistency, testretest reliability, factor validity (structure), convergent and discriminant validity (correlation with corresponding personality patterns and psychopathological symptoms and no relationship to non-corresponding patterns and symptoms), and criteria validity (differences between clinical sample and controls) of the Russian version of the full PBQ. 
Unfortunately for research purposes, the situation in the clinic is a typical one, in that there is not a wide range of personality disorders represented. The sample of 756 outpatients includes only 17 patients with paranoid personality disorder and 20 with narcissistic disorder (like in Beck et al., 2001). In line with the cognitive model of personality disorders (Beck et al., 2015) these people typically have a rather high level of social functioning and seek medical help only under special circumstances like anxiety or depression. They indeed are more vulnerable to stressful situations compared to people with a stable, positive self-conception, but they are rarely inpatients in clinics. This is especially true for people with narcissistic and passiveaggressive beliefs that are contrary to the idea of looking for and receiving help and accepting one's illness. So instead of looking for group with different personality disorders, we concentrated on patients with a wide range of mental illnesses. We hypothesized that:

1. The scores for dysfunctional personal beliefs would be higher in patients with mental illnesses (because of the vulnerability of people with personality disorders to mental symptoms) and at least for some beliefs, they would be most intense in a general group of patients with personality disorders and patients with schizotypal disorder, due to the greatest personality changes in these groups.

2. Both in controls and patients with mental disorders, scores for dysfunctional personality beliefs would be related to a higher level of psychopathological complaints and to corresponding personality patterns according to the Millon Clinical Multiaxial Inventory-III (MCMI-III, Millon, 2009), which is another psychological measure relevant for DSM-IV classification of mental disorders.

\section{Methods}

Data collection was in 2010-2013 and in 2016.

\section{Participants}

The control samples included 591 adults who reported that they have no diagnosis of mental illnesses nor referrals to psychiatrists or psychotherapists due to mental conditions (Table 1). While combining a number of homogeneous samples from different studies may compromise results, we analyzed them both together and separately. In Sample 1, we asked students and working adults from medical and psychological universities to participate in the study; data were collected during personal interviews in 2010. In Samples 2 and 3, in 2016, we asked students from different faculties, as an optional part of their psychological studies, to invite 1-2 people to participate in the study (online through the Google Form platform in Sample 2 and through a personal interview in Sample 3). Taking into account that in Samples 1 and 2, females and younger people dominated, Sample 3 concentrated on males and older people.

Three different clinical groups (200 inpatients with mental illnesses) from different departments of the Mental Health Research Center (Director, Prof. Tatiana P. Klyushnik, M.D.) participated in the study: 
Table 1

Description of samples

\begin{tabular}{lccc}
\hline \multicolumn{1}{c}{ Samples } & $\begin{array}{c}\text { Total } \\
\text { N }\end{array}$ & Males (\%) & $\begin{array}{c}\text { Age: } \text { min - max } \\
\text { (mean } \pm \text { SD) }\end{array}$ \\
\hline $\begin{array}{l}\text { Control samples: } \\
\text { - Sample 1: Validation sample (students and working } \\
\text { adults, psychological and medical professions) }\end{array}$ & 591 & $251(42.6 \%)$ & $\begin{array}{c}17-70 \text { years old } \\
(25.40 \pm 9.58)\end{array}$ \\
- Sample 2: Online sample of adults aged 18-45 & 260 & $80(30.9 \%)$ & $\begin{array}{c}17-60 \text { years old } \\
(21.80 \pm 6.35)\end{array}$ \\
$\begin{array}{l}\text { - Sample 3: Sample of adults of different ages } \\
\text { Clinical samples: }\end{array}$ & 145 & $43(29.7 \%)$ & $\begin{array}{c}18-45 \text { years old } \\
(22.21 \pm 4.37)\end{array}$ \\
$\begin{array}{l}\text { - Clinical Group 1: Patients of the clinic's departments of } \\
\text { "Borderline" Mental Pathology and Affective Disorders }\end{array}$ & 58 & $9(15.9 \%)$ & $\begin{array}{c}17-63 \text { years old } \\
(32.36 \pm 12.36)\end{array}$ \\
$\begin{array}{l}\text { - Clinical Group 2: Young male patients with mood disor- } \\
\text { ders, personality disorders or schizotypal disorder }\end{array}$ & 111 & $111(100 \%)$ & $\begin{array}{c}17-30 \text { years old } \\
(20.24 \pm 3.12)\end{array}$ \\
$\begin{array}{l}\text { - Clinical Group 3: Young male patients recovering after } \\
\text { their first psychotic episode }\end{array}$ & 31 & $31(100 \%)$ & $\begin{array}{c}17-24 \text { years old } \\
(21.00 \pm 2.53)\end{array}$ \\
\hline
\end{tabular}

1. Clinical Group 1 included a wide range of inpatients (predominantly female) from the clinic's departments of "Borderline" Mental Pathology and Affective Disorders. There were $21(36.2 \%)$ patients with anxiety disorders, hypochondriasis, panic or obsessive-compulsive disorders ${ }^{1}$ (F40, F41, F42, F45.2, according to ICD-10), 22 (37.9\%) patients with depression, including bipolar affective disorders with current episode depression (F32, F33, F34.1, F31.3, F31.4), and 15 (25.9\%) patients with schizophrenia or schizotypal disorder (F20, F21).

2. Clinical Group 2 included 111 male youths with nonpsychotic mental illnesses including 44 (39.6\%) patients with mood disorders (F31.3, F31.4, F32, except for F32.2), 34 (30.6\%) patients with personality disorders (F60), and 33 (29.7\%) patients with schizotypal disorder (F21).

3. Clinical Group 3 included 31 male youths recovering after their first psychotic episode (F20.2, F20.3). The length of their recovery period varied from 10 days to one month; they were hospitalized throughout this period.

General exclusion criteria were organic mental disorders, alcoholism or drug dependence, mental retardation or any difficulties of understanding study items due to motivational cognitive or any other deficiency.

Patients in Clinical Group 1 participated in 2016. Patients in Clinical Groups 2 and 3 participated in 2010-2013.

1 All these disorders are described in $\mathrm{CBT}$ as having a common basis in anxiety-related problems

(Beck et al., 2005) 


\section{Procedure}

\section{Questionnaires}

The Personality Beliefs Questionnaire (PBQ) consists of 126 items rated on a 0-3 Likert scale. Each group of 14 items reflects beliefs typical for one personality disorder: avoidant, dependent, passive-aggressive, obsessive-compulsive, antisocial, narcissistic, histrionic, schizoid, and paranoid disorders. The scale for borderline beliefs includes items from different scales. With the permission of Prof. A. Beck (e-mail, 2009) the PBQ was translated into Russian and back-translated. Then the content of the items was discussed by the group of two clinical psychologists and two psychiatrists familiar with the cognitive model of personality disorders. Then they were pilot tested on 15 inpatients who were interviewed about any misunderstandings they may have had during testing. All participants in this study filled out the PBQ.

From the control Sample 2, a total of 110 participants filled out the Symptom Checklist-90 Revised (SCL-90R, Derogatis, 1994) and 78 participants filled out the Millon Clinical Multiaxial Inventory-III (MCMI-III, Millon, 2009). SCL-90R is a symptom checklist including nine scales: Somatization, Obsessive-Compulsive, Interpersonal Sensitivity, Depression, Anxiety, Hostility, Phobic Anxiety, Paranoid Ideation, and Psychoticism, as well as 3 general indices: the Global Severity Index (GSI, measures overall psychological distress), the Positive Symptom Distress Index (PSDI, measures intensity of symptoms), and the Positive Symptom Total (PST, measures a number of symptoms). The MCMI-III includes 14 severe personality patterns corresponding to Axis II in DSM-IV: Schizoid, Avoidant, Depressive, Dependent, Histrionic, Narcissistic, Antisocial, Sadistic, Compulsive, Negativistic (Passive-Aggressive), Masochistic (Self-Defeating), Schizotypal, Borderline, Paranoid. There are also scales for clinical syndromes corresponding to Axis I disorders: Anxiety, Somatoform, Bipolar Manic, Dysthymia, Alcohol Dependence, Drug Dependence, Post-Traumatic Stress Disorder, Thought Disorder, Major Depression, Delusional Disorder.

68 participants from control Sample 3 also filled out the SCL-90R.

54 participants from control Sample 1 filled out the PBQ twice in 3 weeks to assess test-retest reliability.

All 58 patients from clinical group 1 filled out the SCL-90R and MCMI-III. All 111 patients from Clinical Group 2 and 31 patients from Clinical Group 3 filled out the SCL-90R.

Cronbach's alphas for the MCMI-III in our study varied from .63 to .85 for severe personality patterns and $.64-.86$ for clinical syndromes. Cronbach's alphas for SCL-90R scales varied .75-.90.

All participants from the clinical groups signed informed consent for participation in research projects at the Mental Health Research Center, including this study. All participants from the control groups gave their informed consent before participation. The study was conducted in accordance with the Declaration of Helsinki, and the protocol was approved by the Ethics Committee of the Lomonosov Moscow State University Faculty of Psychology; it met the requirements of the Code of Ethics of the Russian Psychological Society.

Data were processed in SPSS Statistics 23.0. 


\section{Results}

\section{Descriptive Statistics, Scales Reliability, and Correlations Between Scales}

Personal beliefs typical of disorders obviously have a mixed structure (Fournier et al., 2012), especially in control samples. Our approach was consistent with that of previous studies (Beck et al., 2001; Fournier et al., 2012), concentrating on discussion of the content validity of the scales and the content differences between them, and then testing correlations between the scales. As shown in Table 2, almost any beliefs were related to each other and this result replicates data of the original PBQ (Beck et al., 2001). For the controls, all the correlations are significant, $\mathrm{p}<.01$. For the clinical samples, all correlations but those of dependent beliefs with antisocial, narcissistic, and schizoid beliefs are significant $(\mathrm{p}<.05)$. Comparison of relationships in the control and clinical samples and in the original validation sample reveals high correlations between avoidant and dependent beliefs, and between narcissistic and histrionic beliefs. This result is similar to the original version and could be explained by the content closeness of these beliefs. Avoidant and dependent beliefs both include the feeling that the person cannot stay alone and cannot create stable, safe relationships. So, people with such beliefs need to avoid close relationships and/or to make others stay with them. People with both narcissistic and histrionic beliefs feel that they need attention and admiration from others. In our samples, narcissistic beliefs are also highly related to antisocial beliefs, which is not typical for American clinical samples, and might be a culture-specific result, which we address below.

Table 2

Pearson's correlations between personality beliefs in the control samples (above the major diagonal) and clinical samples (below diagonal)

\begin{tabular}{|c|c|c|c|c|c|c|c|c|c|c|}
\hline &  &  & 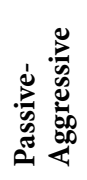 & 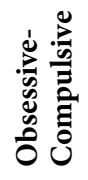 &  &  & 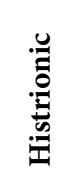 & 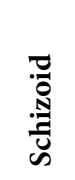 & 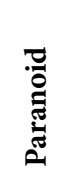 & 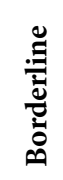 \\
\hline Avoidant & 1 & $.68^{* *}$ & $.29^{* *}$ & $.14^{* *}$ & $.30^{* *}$ & $.36^{*}$ & $.42^{* *}$ & $.25^{* *}$ & $.45^{* *}$ & $.79^{* *}$ \\
\hline Dependent & $.59^{* *}$ & 1 & $.25^{* *}$ & $.12^{* *}$ & $.19^{* *}$ & $.28^{* *}$ & $.47^{* *}$ & -.03 & $.28^{* *}$ & $.67^{* *}$ \\
\hline Passive-Aggressive & $.39^{* *}$ & $.17^{*}$ & 1 & $.35^{* *}$ & $.46^{* *}$ & $.46^{* *}$ & $.46^{* *}$ & $.43^{* *}$ & $.39^{* *}$ & $.39^{* *}$ \\
\hline Obsessive-Compulsive & $.36^{* *}$ & $.24^{* *}$ & $.44^{* *}$ & 1 & $.31^{* *}$ & $.24^{* *}$ & $.18^{* *}$ & $.32^{* *}$ & $.33^{* *}$ & $.21^{* *}$ \\
\hline Antisocial & $.27^{* *}$ & -.01 & $.52^{* *}$ & $.45^{* *}$ & 1 & $.73^{* *}$ & $.50^{* *}$ & $.55^{* *}$ & $.58^{* *}$ & $.49^{* *}$ \\
\hline Narcissistic & $.29^{* *}$ & .04 & $.39^{* *}$ & $.35^{* *}$ & $.68^{* *}$ & 1 & $.70^{* *}$ & $.47^{* *}$ & $.51^{* *}$ & $.47^{* *}$ \\
\hline Histrionic & $.42^{* *}$ & $.33^{* *}$ & $.48^{* *}$ & $.38^{* *}$ & $.48^{* *}$ & $.66^{*}$ & 1 & $.25^{* *}$ & $.39^{* *}$ & $.50^{* *}$ \\
\hline Schizoid & $.33^{* *}$ & -.06 & $.52^{* *}$ & $.34^{* *}$ & $.53^{* *}$ & $.42^{* *}$ & $.24^{* *}$ & 1 & $.58^{* *}$ & $.40^{* *}$ \\
\hline Paranoid & $.49^{* *}$ & $.23^{* *}$ & $.47^{* *}$ & $.37^{* *}$ & $.57^{* *}$ & $.46^{* *}$ & $.40^{* *}$ & $.54^{* *}$ & 1 & $.71^{* *}$ \\
\hline Borderline & $.80^{* *}$ & $.60^{* *}$ & $.47^{* *}$ & $.37^{* *}$ & $.44^{* *}$ & $.38^{* *}$ & $.48^{* *}$ & $.46^{* *}$ & $.74^{* *}$ & 1 \\
\hline
\end{tabular}

Note. ${ }^{*} p<.05,{ }^{* *} p<.01$. 
All the scales demonstrate good consistency across the control and clinical samples (Table 3) although it is a bit lower than for the clinical sample of A. Beck et al. (2001).

Test-retest reliability was high for all the scales (Table 1) and was in general close to the original data ( $\mathrm{r}=.57-.93$, Beck et al., 2001). A paired Student t-test demonstrated that for none of the scales was there a shift in scores in the three weeks between test and retest $(\mathrm{p}>.10)$. However, it should be noted that some effect sizes for the paired Student t-test reached a small effect size (Henson, 2006). Notably, retest scores for dependent, obsessive-compulsive, schizoid, and paranoid beliefs were insignificantly higher in retest, with a small effect size.

Table 3

Descriptive statistics and reliability of $P B Q$ scales in the control and clinical samples (for Cronbach's alphas, variations in the samples are given in parentheses)

\begin{tabular}{|c|c|c|c|c|c|c|c|c|c|}
\hline \multirow{2}{*}{ 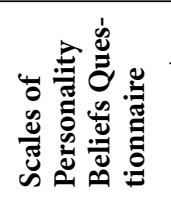 } & \multicolumn{4}{|c|}{ Controls $(N=591)$} & \multicolumn{3}{|c|}{ Clinical sample $(N=200)$} & \multirow{2}{*}{  } & \multirow{2}{*}{ 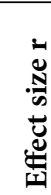 } \\
\hline & Mean & SD & $\begin{array}{l}\text { Cronbach's } \\
\text { alpha }\end{array}$ & $\begin{array}{c}\text { Test-retest } \\
\text { reliability } \mathrm{r} \\
\quad(\mathrm{N}=54)\end{array}$ & Mean & SD & $\begin{array}{l}\text { Cronbach's } \\
\text { alpha }\end{array}$ & & \\
\hline Avoidant & 1.40 & .68 & & & & .73 & & 1.35 & .18 \\
\hline Dependent & 1.50 & .73 & $.86(.84-.88)$ & $.65^{\star *}$ & 2.05 & .78 & $.87(.84$ & -1.61 & .22 \\
\hline $\begin{array}{l}\text { Passive- } \\
\text { Aggressive }\end{array}$ & 2.06 & .60 & .7 & & & .58 & & -.16 & .02 \\
\hline $\begin{array}{l}\text { Obsessive- } \\
\text { Compulsive }\end{array}$ & 2 & .64 & & & & .61 & & 50 & .21 \\
\hline Antisocial & 1.7 & .73 & 8 & 7. & 70 & .72 & 5) & -1.34 & .18 \\
\hline Narcissistic & 1.53 & .79 & $.88(.86-.90)$ & & 1.43 & .66 & $.83(.75-.86)$ & -1.37 & .18 \\
\hline Histrionic & 1.65 & .64 & $.82(.79-.82)$ & & 1.70 & .64 & $.79(.75-.81)$ & -1.02 & .14 \\
\hline Schiz & 1.98 & .61 & $.79(.77-.8$ & $.58^{*}$ & 1. & .59 & $.75(.65-$. & -1.45 & .20 \\
\hline Paranoid & 1.73 & .77 & $.86(.81-.89)$ & 50 & 1.85 & .82 & $.90(.78$ & -1.47 & .20 \\
\hline Borderline & 1.50 & .64 & $.74(.67-.81)$ & $.64^{* *}$ & 1.90 & .69 & $.78(.74-.81)$ & -.36 & .05 \\
\hline
\end{tabular}

Note. ${ }^{*} p<.05,{ }^{* *} p<.01$.

Both in the control and clinical samples, people tended to report obsessivecompulsive and passive-aggressive beliefs (Figure 1). The least reported are avoidant, dependent, narcissistic, and histrionic (as well as borderline) beliefs.

The clinical samples demonstrate higher scores for avoidant, dependent, passive-aggressive, paranoid, and borderline beliefs.

Females held more avoidant, dependent and borderline as well as narcissistic and histrionic beliefs $(\mathrm{t}=-5.58--2.38, \mathrm{p}<.05, \mathrm{r}=.10-.23)$ than males. Most of these differences, except for dependent beliefs $(\mathrm{t}=-5.58, \mathrm{p}<.01, \mathrm{r}=.23)$, disappear in the clinical sample. Moreover, in the clinical sample, females demonstrate 
less narcissistic, histrionic, and antisocial beliefs than males $(t=2.14-4.82, \mathrm{p}<.05$, $\mathrm{r}=.15-.32$ ). Although these differences in the clinical samples could be explained by differences in diagnoses, the data support the assertion that gender differences could be less prominent in the clinical compared to the control samples.

In the control groups, age was weakly related to lower scores for antisocial $(\mathrm{r}=-.21, \mathrm{p}<.01)$, narcissistic $(\mathrm{r}=-.17, \mathrm{p}<.01)$, and histrionic $(\mathrm{r}=-.19, \mathrm{p}<.01)$ beliefs. All other correlations were lower than |.15|. In the clinical groups, older patients demonstrated more dependent beliefs $(\mathrm{r}=.22, \mathrm{p}<.01)$ and less antisocial $(\mathrm{r}=-.20, \mathrm{p}<.01)$ and narcissistic beliefs $(\mathrm{r}=-.18, \mathrm{p}<.05)$.

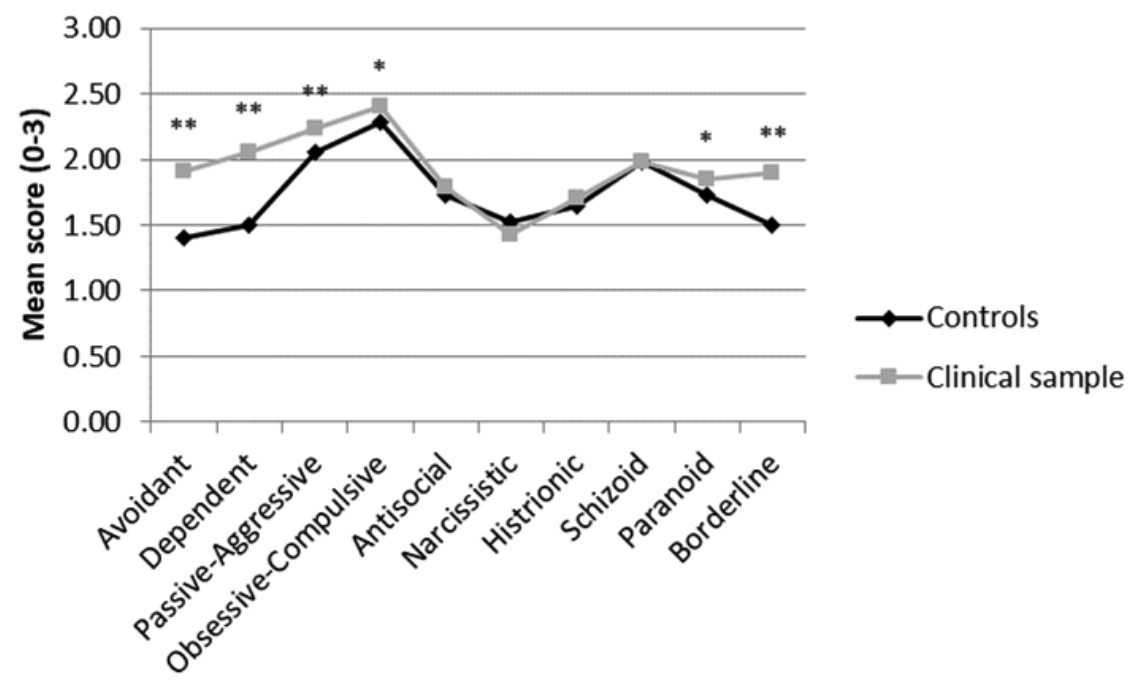

Figure 1. Control and clinical profiles of personality beliefs.

${ }^{\star} \mathrm{p}<.05,{ }^{* *} \mathrm{p}<.01$.

\section{Personal Beliefs in Mental Illnesses}

The patients in Clinical Group 1 compared to the controls have higher scores for avoidant, dependent, and borderline beliefs $\left(\mathrm{F}=5.66-23.32, \mathrm{p}<.01, \eta^{2}=.03-.10\right)$, but lower scores for antisocial and narcissistic beliefs $\left(\mathrm{F}=5.96, \mathrm{p}<.01, \eta^{2}=.03\right.$ and $\mathrm{F}=8.33, \mathrm{p}<.01, \eta^{2}=.04$, respectively). However, according to post hoc Scheffe comparisons, the differences in avoidant and dependent beliefs are explained by differences between patients and controls, while patients with anxiety, depression, schizophrenia, and schizotypal disorder do not differ from each other. There are no post hoc differences in borderline beliefs among the three clinical subgroups and controls. Between-group differences in antisocial and narcissistic beliefs are explained by their lower scores in depressive patients compared to the controls $(\mathrm{p}<.05)$. Comparisons of patients with depression, anxiety, and schizophrenia/ schizotypal disorder reveal no differences in beliefs.

To study personal beliefs in Clinical Groups 2 and 3, we have chosen from the control groups 185 males 30 years old or younger. The patients with mental disorders, especially schizotypal disorder, hold more avoidant, dependent, passiveaggressive, histrionic, and borderline beliefs than the controls. Post hoc Scheffe 
comparisons demonstrate that the controls have less avoidant and borderline beliefs than patients with mood, personality, and schizotypal disorders and patients experiencing remission after a psychotic episode $(\mathrm{p}<.05)$. Schizotypal patients also have higher scores for borderline beliefs than patients who have experienced psychosis $(\mathrm{p}<.05)$. For dependent beliefs, the controls significantly differ from the patients in mood disorder, schizotypal disorder, and psychosis, but not personality disorders. However, there are no post hoc between-group differences for passiveaggressive and histrionic beliefs. Moreover, there is no evidence of differences between the different kinds of illnesses.

Comparisons of clinical subgroups only showed significant differences in dependent and borderline beliefs $\left(\mathrm{F}=2.81-3.58, \mathrm{p}<.05, \eta^{2}=.07-.09\right)$ and marginally significant differences in narcissistic and obsessive-compulsive beliefs $\left(\mathrm{F}=2.18-2.39, \mathrm{p}<.10, \eta^{2}=.06\right)$. Scores for dependent and narcissistic beliefs are higher in schizotypal disorder, while scores for borderline beliefs are higher in schizotypal and mood disorders. Scores for obsessive-compulsive beliefs are higher in schizotypal disorder and those in remission after psychosis. The only post hoc difference that reaches significance is a higher score for borderline beliefs in patients with schizotypal disorder compared to patients in remission after psychosis.

Table 4

Comparisons of young male patients with mental illnesses and controls

\begin{tabular}{|c|c|c|c|c|c|c|c|c|c|c|c|c|}
\hline \multirow{2}{*}{$\begin{array}{c}\text { Personal } \\
\text { beliefs }\end{array}$} & \multicolumn{2}{|c|}{ Controls } & \multicolumn{2}{|c|}{$\begin{array}{c}\text { Mood } \\
\text { disorders }\end{array}$} & \multicolumn{2}{|c|}{$\begin{array}{c}\text { Perso- } \\
\text { nality } \\
\text { disorders }\end{array}$} & \multicolumn{2}{|c|}{$\begin{array}{c}\text { Schizo- } \\
\text { typal } \\
\text { disorder }\end{array}$} & \multicolumn{2}{|c|}{$\begin{array}{l}\text { Remission } \\
\text { after psy- } \\
\text { chotic } \\
\text { episode }\end{array}$} & \multirow{2}{*}{ 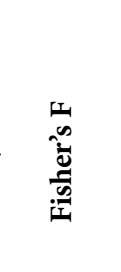 } & \multirow{2}{*}{ 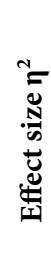 } \\
\hline & $\sum_{\text {ฮี }}^{\tilde{\Sigma}}$ & के & 危 & क & $\stackrel{\Xi}{\Xi}$ & क & $\sum_{\Sigma}^{\Xi}$ & क & $\stackrel{\Xi}{\Xi}$ & क & & \\
\hline Avoidant & 1.23 & .66 & 1.99 & 78 & 1.76 & .74 & 2.19 & .72 & 1.79 & .74 & $19.15^{\star *}$ & .21 \\
\hline Dependent & 1.35 & .65 & 1.91 & .73 & 1.70 & .80 & 2.29 & .83 & 1.92 & .70 & $14.93^{\star *}$ & .17 \\
\hline $\begin{array}{l}\text { Passive- } \\
\text { Aggressive }\end{array}$ & 2.01 & .64 & 2.12 & .47 & 2.31 & .62 & 2.35 & .61 & 2.19 & .55 & $3.63^{* *}$ & .05 \\
\hline $\begin{array}{l}\text { Obsessive- } \\
\text { Compulsive }\end{array}$ & 2.32 & .66 & 2.47 & .63 & 2.21 & .64 & 2.53 & .71 & 2.53 & .57 & $2.32^{\mathrm{T}}$ & .03 \\
\hline Antisocial & 1.79 & .73 & 1.92 & .63 & 2.04 & .59 & 1.97 & .69 & 2.09 & .67 & 1.84 & .02 \\
\hline Narcissistic & 1.51 & .77 & 1.51 & .52 & 1.51 & .52 & 1.85 & .64 & צס & .59 & 1.56 & .02 \\
\hline Histrionic & 1.57 & .64 & 1.72 & .52 & 1.77 & .57 & 1.93 & .65 & 1.85 & .64 & $3.62^{* *}$ & .05 \\
\hline Schizoid & 1.97 & .64 & 2.03 & .52 & 2.11 & .71 & 2.13 & .47 & 1.91 & .53 & .75 & .01 \\
\hline Paranoid & 1.76 & .83 & 1.95 & .69 & 1.83 & .89 & 2.26 & .73 & 1.94 & .62 & $2.08^{\mathrm{T}}$ & .03 \\
\hline Borderline & 1.44 & .62 & 2.01 & .64 & 1.85 & .57 & 2.24 & .75 & 1.70 & .68 & $14.00^{\star *}$ & .16 \\
\hline
\end{tabular}

Note. ${ }^{T} p<.10,{ }^{*} p<.05,{ }^{* *} p<.01$. 


\section{Personal Beliefs and Personality Patterns}

In general, higher scores for dysfunctional personality beliefs are related to stronger general psychopathological complaints (Table 5). In particular, avoidant, dependent, paranoid, and borderline beliefs are strongly correlated with psychopathological complaints both in the control and clinical samples. We could not find any stable pattern of correlations for narcissistic, schizoid, obsessive-compulsive, or antisocial beliefs, so we did not include them in the table.

Table 5

Personal beliefs and psychopathological symptoms

\begin{tabular}{|c|c|c|c|c|c|c|}
\hline $\begin{array}{c}\text { Scales } \\
\left(N_{\text {norm }}=178 /\right. \\
\left.N_{\text {clinic }}=200\right)\end{array}$ &  & 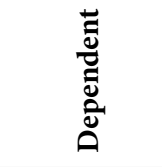 & 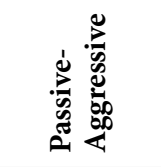 & 号 & 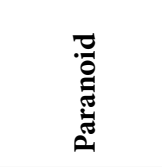 & : \\
\hline $\begin{array}{l}\text { SCL-90R - Soma- } \\
\text { tization }\end{array}$ & $.42^{\star \star} / .14$ & $.34^{\star *} / .24^{\star *}$ & $.21^{\star *} / .10$ & $.32^{\star *} / .12$ & $.33^{\star *} / .20^{\star *}$ & $.47^{* *} / .26^{* *}$ \\
\hline $\begin{array}{l}\text { SCL-90R - } \\
\text { Obsessiveness- } \\
\text { Compulsiveness }\end{array}$ & $.60^{* *} / .37^{\star *}$ & $.55^{* *} / .35^{\star *}$ & $.25^{\star *} / .18^{\star}$ & $.29^{* *} / .13$ & $.36^{\star *} / .33^{\star *}$ & $1.46^{* *}$ \\
\hline $\begin{array}{l}\text { SCL-90R - Interper- } \\
\text { sonal sensitivity }\end{array}$ & $.66^{\star *} / .43^{* *}$ & $.54^{\star *} / .38^{\star *}$ & $.20^{\star \star} / .21^{\star \star}$ & $.30^{* *} / .22^{* *}$ & $.47^{\star *} / .36^{* *}$ & $.69^{\star *} / .53^{\star *}$ \\
\hline $\begin{array}{l}\text { SCL-90R - Depres- } \\
\text { sion }\end{array}$ & $.57^{\star *} / .29^{\star *}$ & $.52^{\star *} / .29^{\star *}$ & $.31^{\star *} / .10$ & $.28^{\star *} / .12$ & $.36^{\star *} / .31^{\star *}$ & $.63^{* *} / .40^{* *}$ \\
\hline SCL-90R - Anxiety & $.51^{\star *} / .31^{\star *}$ & $.44^{* *} / .29^{* *}$ & $.26^{\star *} / .17^{\star}$ & $.31^{\star *} / .15$ & $.35^{* *} / .28^{* *}$ & $.56^{* *} / .36^{* *}$ \\
\hline SCL-90R - Hostility & $.42^{\star \star} / .20^{\star \star}$ & $.24^{\star *} / .21^{\star *}$ & $.26^{\star *} / .27^{\star *}$ & $.37^{\star *} / .16^{\star}$ & $.35^{\star *} / .27^{\star *}$ & $.45^{\star \star} / .34^{\star \star}$ \\
\hline SCL-90R - Phobia & $.50^{\star *} / .28^{\star *}$ & $.37^{\star *} / .35^{\star *}$ & $.12 / .19^{\star}$ & $.13 / .21^{\star *}$ & $.34^{\star *} / .29^{\star *}$ & $.51^{\star *} / .37^{\star *}$ \\
\hline SCL-90R - Paranoia & $.44^{* *} / .34^{* *}$ & $.30^{* *} / .25^{* *}$ & $.31^{* *} / .34^{* *}$ & $.41^{* *} / .24^{* *}$ & $.52^{\star \star} / .47^{\star \star}$ & $.57^{\star *} / .51^{* *}$ \\
\hline $\begin{array}{l}\text { SCL-90R - Psycho- } \\
\text { ticism }\end{array}$ & $.53^{\star *} / .31^{\star *}$ & $.51^{\star *} / .30^{\star *}$ & $.21^{\star *} / .18^{\star}$ & $.34^{* *} / .17^{\star}$ & $.45^{\star \star} / .30^{\star *}$ & $.63^{\star *} / .41^{\star *}$ \\
\hline $\begin{array}{l}\text { SCL-90R - Positive } \\
\text { Symptom Distress } \\
\text { Index }\end{array}$ & $.63^{\star *} / .34^{\star *}$ & $.53^{\star *} / .34^{\star *}$ & $.29^{\star *} / .21^{\star *}$ & $.37^{\star *} / .18^{\star}$ & $.45^{\star *} / .36^{\star *}$ & $.70^{\star *} / .46^{\star *}$ \\
\hline $\begin{array}{l}\text { SCL-90R - Positive } \\
\text { Symptom Total }\end{array}$ & $.59^{\star *} / .37^{\star *}$ & $.50^{* *} / .32^{\star *}$ & $.27^{\star \star} / .22^{\star \star}$ & $.35^{* *} / .22^{* *}$ & $.44^{\star *} / .37^{\star *}$ & $.64^{\star *} / .48^{\star *}$ \\
\hline $\begin{array}{l}\text { SCL-90R - Global } \\
\text { Severity Index }\end{array}$ & $.51^{\star *} / .24^{\star *}$ & $.41^{\star *} / .27^{\star *}$ & $.29^{* * / .14}$ & $.34^{* *} / .05$ & $.33^{\star *} / .20^{\star *}$ & $.54^{\star *} / .32^{\star *}$ \\
\hline
\end{tabular}

Note. ${ }^{*} p<.05,{ }^{* *} p<.01$. Correlations that are discussed in the text are boldfaced

Correlations between paranoid beliefs and paranoia and psychoticism are high but not the highest ones. However, obsessive-compulsive beliefs have low correlation with obsessiveness-compulsiveness $(\mathrm{r}=.12$ in both clinical and control 


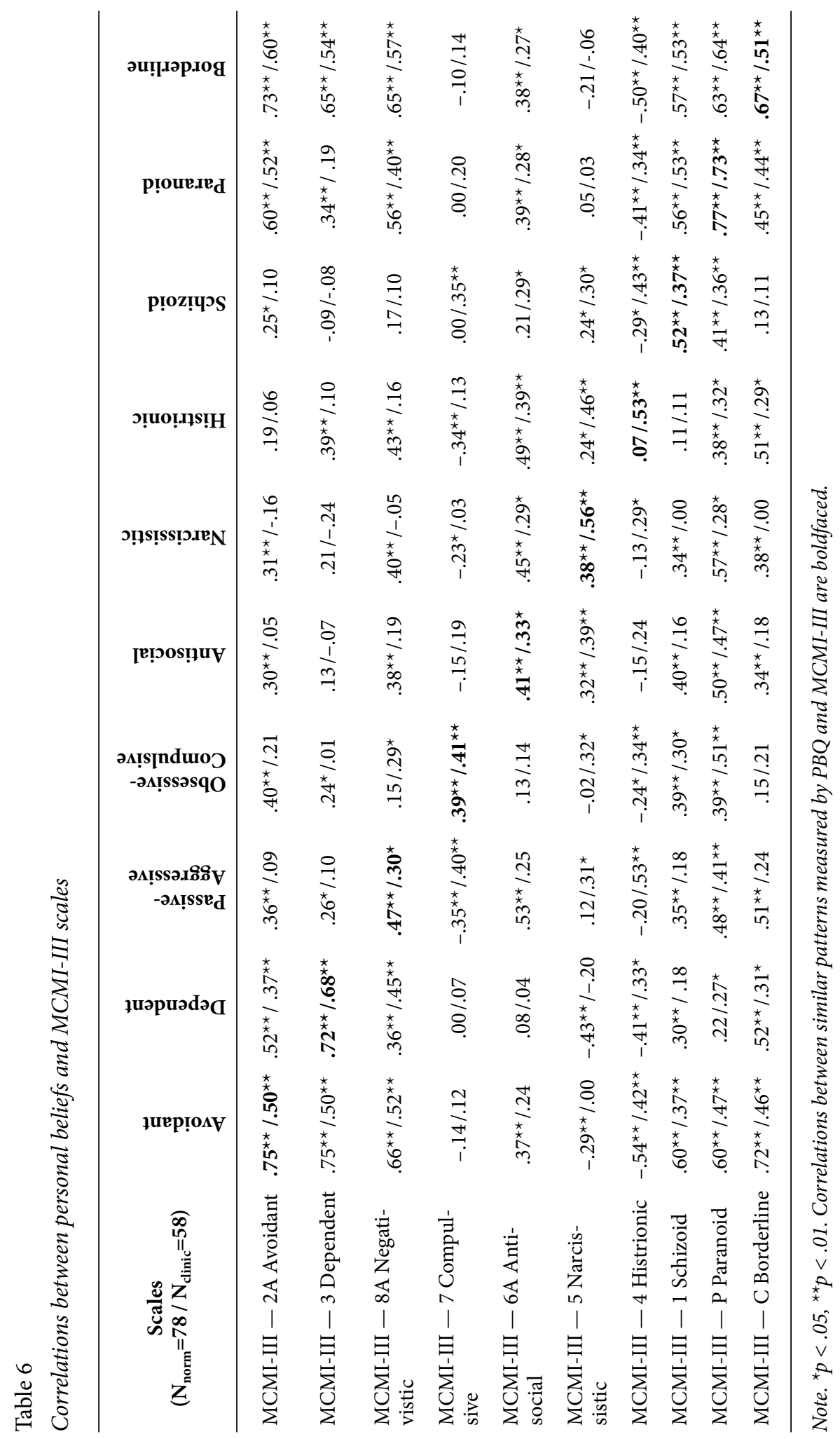


groups); schizoid beliefs are unrelated to psychoticism $(\mathrm{r}=.19$ and $\mathrm{r}=.12$, respectively). Relationships between hostility and passive-aggressive beliefs are not the highest, while relationships between hostility and antisocial beliefs are low for the control sample and non-significant for the clinical sample $(r=.23$ and $r=.11$, respectively).

As can be seen in Table 6, comparison between the PBQ and the MCMI-III gives better results in terms of scale specificity. For schizoid, avoidant, dependent, narcissistic, antisocial, compulsive, paranoid, and borderline beliefs, correlations with similar MCMI-III patterns are among the highest both in the control and clinical groups. For histrionic beliefs, there was a correlation with the histrionic clinical pattern, but in the clinical sample only. The only correlations that are not so high compared to other beliefs are related to passive-aggressive beliefs, although these are positive and significant. The passive-aggressive pattern is more closely related to avoidant, paranoid, and borderline beliefs.

\section{Discussion}

The Russian version of the PBQ demonstrates good reliability and test-retest validity, although they both are a bit lower than the original PBQ data (Beck et al., 2001) and Russian Borderline Scale data. In particular, in our clinical and control samples, Cronbach's alpha for the Borderline Scale were $.74-.78$ versus .89 (Konina \& Kholmogorova, 2016; Butler et al., 2002) and test-retest correlation was .64 versus .78. Nevertheless, all these results indicate good reliability and consistency and are close to the results of other PBQ-based studies (Bhar et al., 2012), pointing to consistency as .77-.94 and test-retest reliability as .57-.93.

In general, both in the control and clinical samples, people tend to report obsessive-compulsive and passive-aggressive beliefs and deny narcissistic and histrionic (as well as borderline) beliefs. This is reasonable because obsessive-compulsive beliefs in Russian culture include people's attempts to do their best and to eliminate mistakes, while passive-aggressive beliefs describe a tendency not to demonstrate aggression even though it is there. Narcissistic and histrionic beliefs, however, refer to the subjective importance of attention and admiration, so it could be socially desirable to deny them. In the control sample, the least reported are also avoidant and dependent beliefs. There are gender differences in personality beliefs in the control sample that disappear in the clinical sample (except for dependent beliefs); in general, females are more avoidant, dependent, borderline, narcissistic, and histrionic compared to males. Age is only weakly related to beliefs.

Beliefs systems seem not to be highly differentiated in people, both in the original version (Beck et al., 2001) and in our study. This is especially true for avoidant and dependent beliefs $(\mathrm{r}=.59-.73)$ as well as for narcissistic and histrionic beliefs $(\mathrm{r}=.64-.70)$. Theoretically this result is reasonable, given common closeness-related problems for the first two beliefs and common attention- and acknowledgement-related problems for the latter two. In the Russian samples, there are high correlations between antisocial and narcissistic beliefs $(r=.68-.73)$ which might be a culture-specific result. Compared to American culture, where self-presentation, defending one's own interests, and achievement are perceived as positive traits, in Russian culture these traits are perceived as individualistic, selfish, and aggressive, 
so admission of such beliefs could be perceived as admission of readiness for aggression and competition at any price.

Although we did not compare subsamples with different personality disorders (Beck et al., 2001), we could replicate the general finding that patients with mental illness demonstrate higher scores for avoidant, dependent, passive-aggressive, paranoid, and borderline beliefs, and probably (in one subsample) histrionic beliefs. Understanding personality patterns in different mental disorders is especially important given their relationship to illness representation and adherence to treatment (Rasskazova, 2018). However, we did not find any stable differences between patients with different disorders that could indicate low specificity of the PBQ's scales for different mental disorders in general clinical practice. Moreover, the results from Clinical Sample 1 suggest an even lower level of antisocial and narcissistic beliefs in patients with depression compared to controls. However, as a support of PBQ specificity, previous empirical findings (Beck et al., 2001; Butler et al., 2002; Fournier et al., 2012) strongly support differences in personal beliefs in patients with avoidant, dependent, obsessive-compulsive, narcissistic, paranoid, histrionic, passiveaggressive, avoidant, antisocial, and borderline disorders, while our results suggest that high scores for a wide range of beliefs (avoidant, dependent, passive-aggressive, obsessive-compulsive, paranoid, and borderline) could be typical of patients with schizotypal disorder. It should be noted that differentiation of schizotypal disorder from other disorders is a relevant clinical task and psychological diagnostics could be practically helpful in this sphere, especially in studies of those at high risk for psychosis and of its prevention (Rasskazova \& Friedberg, 2012).

Possible clarification of the uses of the PBQ in differentiation of groups of patients comes from the study of its convergent and discriminant validity. Comparisons with MCMI-III clinical personality patterns reveal strong evidence of the validity and specificity of the PBQ scales, while comparisons with the SCL-90R reveal strong positive correlations of almost all beliefs with almost all psychopathological symptoms (and has been replicated for the Russian Borderline Scale [Konina \& Kholmogorova, 2016], although correlations in our clinical and control samples were a bit higher). In particular, such specific relationships were found for the Avoidant, Dependent, Schizoid, Obsessive-Compulsive, Narcissistic, Paranoid, and Borderline scales and - in the Clinical Group only - for the Histrionic scale. Passiveaggressive and antisocial beliefs were related to Negativistic and Antisocial patterns from the MCMI but were more closely related to the Paranoid pattern. In line with the cognitive theory of personality disorders (Beck et al., 2015), it is reasonable to suggest that there are specific personality patterns that are consistently measured by different instruments (e.g., the MCMI and PBQ), patterns which are especially high in patients with such personality disorders. However in general, the control or clinical samples of most of such personality beliefs show that the beliefs lead to mental vulnerability and a general increase in psychopathological symptoms that has been called "demoralization" in some studies (e.g., Tellegen et al., 2008).

\section{Conclusion}

Thus Russian version of the PBQ is a reliable, stable, and valid instrument both in the control and clinical samples. Higher scores for avoidant, dependent, passive- 
aggressive, paranoid, and borderline beliefs, and probably histrionic beliefs, are typical for patients with different mental illnesses compared to the control sample, while especially high scores for avoidant, dependent, passive-aggressive, obsessivecompulsive, paranoid, and borderline beliefs are prominent in patients with schizotypal disorder. Further studies could test whether these results could be helpful for differential diagnosis of schizotypal disorders in clinical practice.

Although appropriate testing of the specificity of the PBQ scales requires samples with different personality disorders, we found (in line with previous findings) that both in the control and clinical samples, dysfunctional beliefs have a mixed structure, with high interference between avoidant and dependent, passive-aggressive and schizoid, narcissistic and histrionic beliefs. Moreover, dysfunctional beliefs seem to be related not to specific psychopathological complaints, but to a general level of psychological "demoralization". Nevertheless, specific relationships of the PBQ scales with corresponding clinical personality patterns confirm their convergent and discriminant validity.

\section{Limitations}

The major limitation of the study is the absence of large specific groups of patients with different personality disorders. This limitation is explained by the low rate of such patients in mental health clinics (Beck et al., 2001). Although this limitation could compromise our conclusion about the partial specificity of the PBQ scales, the conclusion has support from previous data on high inter-scale correlations and mixed structure (Fournier et al., 2015) and high scores on a number of beliefs in patients with mood disorders (e.g., Yucens et al., 2014). Moreover, the problem of the PBQ scales' convergent validity and specificity is still discussed in the literature and some authors have suggested a modified version of the PBQ (Zavadski et al., 2017). Another limitation is the heterogeneity of samples (especially clinical samples), which was addressed in the paper by comparisons of psychometric characteristics for a general sample and subsamples separately. The cross-sectional design of the study limits our conclusion about the direction of relationships between mental illnesses and cognitive beliefs that are proposed in A.T. Beck's model. Further research could concentrate on the specificity of dysfunctional beliefs both in a control sample and in patients with different mental disorders. Also, there is a limitation in terms of sampling: this paper reported data on several samples from different years, using slightly different design. Some of these samples are smaller than 100 participants (e.g., 78 control subjects and 58 patients filled out the MCMI-III). Although following A. Beck (Beck et al., 2015), we see no reason to expect differences in personal beliefs from 2010 to 2016, and comparisons between the samples revealed no such differences, it could be taken into account in further studies.

\section{Acknowledgements}

The study was supported by a grant of the President of the Russian Federation for the state support of young Russian scientists, project No. MK-2193.2017.6, "Psychodiagnostics of personality beliefs in norm and pathology". 
The author is grateful to Dr. Prof. Vasiliy G. Kaleda, Dr. Alexandra N. Barkhatova, PhD., Dr. Maria A. Omel'chenko, PhD., and Prof. Alexander Sch. Tkhostov for their help in the organization of the clinical part of the study; to graduate student Jana M. Zhorina who participated in some clinical data collection; and to PhD. Ilia V. Pluzhnikov who participated in some online control data collection.

\section{References}

Aktas, E., Guriz, O.S., Alpaslan, G., Cavdar, E., \& Orsel, S. (2015). Comparing diagnostic tools in personality disorders. Klinik Psikofarmakoloji Bulteni [Bulletin of Clinical Pharmacology], 25 (S1), S157-S158. In Turkish.

Albein-Urios, N., Martinez-González, J.M., \& Lozano, Ó. (2014). Monetary delay discounting in gambling and cocaine dependence with personality comorbidities. Addictive Behaviors, 39(11), 1658-1662. http://dx.doi.org/10.1016/j.addbeh.2014.06.001

Beck, A.T., Butler, A.C., Brown, G.K., Dahlsgaard, K.K., Newman, C.F., \& Beck, J.S. (2001). Dysfunctional beliefs discriminate personality disorders. Behaviour Research and Therapy, 39, 1213-1225. http://dx.doi.org/10.1016/S0005-7967(00)00099-1

Beck, A.T., Davis, D.D., \& Freeman, A. (Eds.). (2015). Cognitive therapy of personality disorders. Third edition. New York: Guilford Press.

Beck, A.T., Emery, G., \& Greenberg, R.L. (2005). Anxiety disorders and phobia: A cognitive perspective. New York, NY, US: Basic Books.

Bhar, S.S., Beck. A.T., \& Butler, A.C. (2012). Beliefs and personality disorders: An overview of the personality beliefs questionnaire. Journal of Clinical Psychology, 68(1), 88-100. http://dx.doi.org/10.1002/jclp.20856

Butcher, J. N., Graham, J. R., Ben-Porath, Y. S., Tellegen, A., Dahlstrom, W. G., \& Kaemmer, B. (2001). MMPI-2 (Minnesota Multiphasic Personality Inventory-2): Manual for administration and scoring (2nd ed.). Minneapolis, MN: University of Minnesota Press. https://doi.org/10.1037/t15120-000

Butler A.C., Brown G.K., Beck A.T., \& Grisham J.R. (2002). Assessment of dysfunctional beliefs in borderline personality disorder. Behaviour Research Therapy, 40, 1231-1240. http://dx.doi.org/10.1016/S0005-7967(02)00031-1

Butler, A.C., Beck, A.T., \& Cohen, L.H. (2007). The Personality Belief Questionnaire Short Form: Development and preliminary findings. Cognitive Therapy and Research, 31, 357-370. http://dx.doi.org/10.1007/s10608-006-9041-x

Derogatis, L.R. (1994). Symptom Checklist-90-Revised: Administration, scoring \& procedures manual. Minneapolis, MN: Pearson.

Fournier, J.C., DeRubeis, R.G., \& Beck, A.T. (2012). Dysfunctional cognitions in personality pathology: The structure and validity of the Personality Belief Questionnaire. Psychological Medicine, 42(4), 795-805. http://dx.doi.org/10.1017/S0033291711001711

Henson, R. K. (2006). Effect-size measures and meta-analytic thinking in counseling psychology research. The Counseling Psychologist, 34(5), 601-629. http://doi.org/10.1177/0011000005283558

Hernández, M., Darío, R., Vasquez, M., \& Semenova, N. (2015). Psychometric properties and structural validity of the short version of the Personality Beliefs Questionnaire (PBQ-SF). International Journal of Psychological Research, 8(2), 49-60. https://doi.org/10.21500/20112084.1509

Kargin, A.M., Kholmogorova, A.B., \& Vojtseh, V.F. (2009). Lichnostnye faktory suitsidal'nogo povedeniya u patsientov krizisnogo statsionara, sovershivshikh suitsidal'nye popytki [Personality factors of suicidal behavior in crisis ward patients who have attempted to commit suicide. Sotsialnaya i klinicheskaya psikhiatriya [Social and Clinical Psychiatry], 19(4), 15-20. (In Russian, abstract in English.)

Kernberg, O.F. (1984). Severe personality disorders: Psychotherapeutic strategies. New Haven, CT: Yale University Press.

Konina, M.A., \& Kholmogorova, A.B. (2016). Oprosnok disfunktsional'nykh ubezhdenii pri pogranichnom rasstroistve lichnosti (PBQ-BPD): adaptatsia dlia russkoiazychnoi vyborki [The Personality Beliefs Questionnaire in borderline personality disorder (PBQ-BPD): Adaptation for a Russian-speaking sample. Konsul'tativnaya psikhologiya i psikhoterapiya [Counseling Psy- 
chology and Psychotherapy], 24(3), 126-143. (In Russian, abstract in English.). http://dx.doi. org/10.17759/cpp.2016240308

Maximov, A.M., \& Kholmogorova, A.B. (2011). Sotsial'nye i psikhologicheskie aspekty fenomena muzhskoi prostitutsii v sovremennoi kul'ture [Social and psychological aspects of the phenomenon of male prostitution in modern culture]. Культурно-историческая психология [Cultural-Historical Psychology], 1, 80-90. (In Russian, abstract in English.)

Millon, T. (2009). Millon Clinical Multiaxial Inventory - III. Manual. Fourth Edition. NY: Pearson.

Moretti, L., Trógolo, M., Dominguez-Lara, S.A., Conn, H., \& Medrano, L.A. (2017). Factor structure and reliability of the Personality Belief Questionnaire in Argentina. Archives of Psychiatry \& Psychotherapy, 20(3), 79-86. http://dx.doi.org/10.12740/APP/92644.

Nikitina, I.V., Kholmogorova, A.B., \& Krasnova, V.V. (2012). Sotsial'naya trevozhnost' u patsientov s rasstroistvami affektivnogo spektra [Social anxiousness in patients with affective spectrum disorders]. Sotsial'naya i klinicheskaya psikhiatriya [Social and Clinical Psychiatry], 22(3), 30-35. (In Russian, abstract in English.)

Rasskazova E.I. (2018). Kognitivnaya i emotsional'naya sostavliayushchie reprezentatsii bolezni pri psikhicheskikh rasstroistvakh: rol' lichnostnyx osobennostei [Cognitive and emotional components of illness representation in mental disorders: The role of personality]. Psikhologicheskie Issledovaniya [Psychological Studies], 11(57), 7 (In Russian, abstract in English.) URL: http://psystudy.ru/index.php/eng/2018v11n57e/1540-rasskazova57e.html

Rasskazova, E., \& Friedberg, R. (2012). Cognitive behavioral therapy for psychosis prevention and treatment for youth. Current Psychiatry Reviews, 12(1), 79-87. http://dx.doi.org/10.2174/1573400511666150930232543

Ryan, R.B., Kumar, V. K., \& Wagner, K (2015).The Personality Beliefs Questionnaire-Short-Form: Relationship of personality disorders schemata with entitlement and dysfunctional thoughts. Current Psychology: A Journal for Diverse Perspectives on Diverse Psychological Issues, 34(2), 239-247. http://dx.doi.org/10.1007/s12144-014-9254-1

Sokolova, E.T. (2015). Klinicheskaya psikhologiya utraty Ya [Clinical psychology of the loss of Self]. Moscow: Smysl.

Taymur, I., Ozdel, K., Gundogdu, I., Efe, C., Tulaci, R., \& Kervancioglu, A. (2015). Personality-related core beliefs in patients diagnosed with fibromyalgia plus depression: A comparison with depressed and healthy control groups. Nordic Journal of Psychiatry, 69(5), 386-391. http://dx.doi. org /10.3109/08039488.2014.990510

Tellegen, A., Ben-Porath, Y. S., McNulty, J. L., Arbisi, P. A., Graham, J. R., \& Kaemmer, B. (2008). The MMPI-2 restructured clinical scales: Development, validation, and interpretation. Minneapolis: University of Minnesota Press.

Thimm, J.C., Jordan, S., \& Bach, B. (2016).The Personality Inventory for DSM-5 Short Form (PID-5SF): Psychometric properties and association with big five traits and pathological beliefs in a Norwegian population. BMC Psychology, 4, ArtID: 61. http://dx.doi.org/10.1186/s40359-016-0169-5

Yucens B., Kuru E., Safak Y., Karadere, M.E., \& Turkcapar M. (2014). Comparison of personality beliefs between depressed patients and healthy controls. Comprehensive Psychiatry, 55 (8), 19001905. http://dx.doi.org/10.1016/j.comppsych.2014.07.020

Zawadski, B., Popiel, A., Praglowska, E., \& Newman, C. (2017). Specificity of dysfunctional beliefs in personality disorders: psychometric characteristics of the Polish translation and modified version of the Personality Beliefs Questionnaire (PBQ). Annals of Psychology, 20(2), 355-372. http://dx.doi.org/10.18290/rpsych.2017.20.2-4en

Original manuscript received November 14, 2019 Revised manuscript accepted July 23, 2020 First published online September 15, 2020

To cite this article: Rasskazova, E.I. (2020). Beck's Personality Beliefs Questionnaire: Evidence of Validity and Reliability of the Russian Version. Psychology in Russia: State of the Art, 13(3), 34-50. DOI: $10.11621 /$ pir.2020.0303 